\title{
Disputas, negociações e tensões: sobre a emergência do Instituto de Educação de Belford Roxo, RJ'
}

\author{
Disputes, negotiations and strains: the emergency of Instituto de \\ Educação de Belford Roxo, RJ
}

\section{Disputas, negociaciones y tensiones: sobre la emergencia del Instituto de Educación de Belford Roxo, RJ}

\author{
José Cláudio Sooma Silua ${ }^{2}$ \\ Universidade Federal do Rio de Janeiro, Professor Adjunto de História da Educação e do \\ Programa de Pós-Graduação \\ Andréa Miguel Abrantes Ferreira ${ }^{3}$ \\ Faculdade de Belford Roxo, Professora e Psicopedagoga
}

Resumo: Neste artigo se dialoga com um conjunto de pesquisas em História da Educação que selecionou as políticas públicas de educação e as diferentes experiências de formação docente como temáticas de estudo. De modo mais específico, o foco foi direcionado para o Instituto de Educação (Centro Integrado de Educação Pública - CIEP Brizolão 380 Joracy Camargo) localizado no Município de Belford Roxo, RJ, tendo como recorte temporal os anos 1996 a 2006. Nessa linha, foram problematizadas algumas das dimensões que teriam impulsionado a inauguração dessa Instituição de Ensino voltada para trabalhar a formação docente em Nível Médio no mesmo período em que tanto o Município se emancipava quanto era promulgada a LDB n. 9.394/96, que enfatizava a necessidade de que os professores que fossem atuar (ou já atuassem) na Educação Básica tivessem Curso Superior.

Palavras-chave: História da Educação. Instituto de Educação. Formação de professores. Belford Roxo.

Este texto, de forma resumida, foi apresentado no IX Congresso Brasileiro de História da Educação ocorrido na Universidade Federal da Paraíba em agosto de 2017. Para o desenvolvimento do estudo, contamos com o apoio financeiro do CNPq e da FAPERJ.

2 Doutor em Educação pela Universidade do Estado do Rio de Janeiro; Mestre em Educação pela Universidade de São Paulo.

3 Mestre em Educação pela Universidade Federal do Rio de Janeiro; Pós-graduada nas seguintes áreas: Psicopedagogia, Filosofia, Orientação Educacional, Supervisão Educacional, Psicomotricidade, Administração/Planejamento da Educação e MBA em Gestão de Instituições Educacionais. 
Abstract: This article comprises a series of researches in History of Education that have selected public educational policies and different experiences of teacher training as subjects of study. The focus of this study is the Educacional Institute (CIEP Brizolão 380 Joracy Camargo), located in the Municipality of Belford Roxo, RJ, between the period of 1996 to 2006. Concerning this scope, some questions arouse regarding the reasons that boosted the opening of this Educational Institute directed to work with teacher training on High School level. Furthermore, the inauguration occured during a period in which two important events were taking place: the Municipality emancipation and the enactment of LDB n. 9.394/96 that emphasized the necessity of a University degree for all teachers working in the Basic Education.

Keywords: History of Education. Educacional Institute. Teacher training. Belford Roxo.

Resumen: El artículo corresponde a un conjunto de investigaciones en Historia de la Educación que seleccionó las políticas públicas de educación y de las distintas experiencias en la formación docente como temáticas de estudio. De manera más específica, la base fue dirigida al Instituto de Educación (CIEP Brizolão 380 Joracy Camargo), ubicado en el Municipio de Belford Roxo, RJ, teniendo como extracto que data de los años 1996 al 2006. En esta misma línea, fueron algunas de las dimensiones que habrían impulsado a la inauguración de esa Institución de Enseñanza enfocada para trabajar en la formación docente en Nivel Medio en el mismo período en que el Municipio se expandía y que a la vez se promulgaba la LDB n. 9.394/96 que enfatizaba la necesidad de que los profesores se desempeñen (o bien que desempeñarán) en la Educación Básica tuvieran enseñanza superior.

Palabras clave: Historia de la Educación. Instituto de Educación. Formación de profesores. Belford Roxo.

\section{INTRODUÇÃO}

No presente trabalho se estabeleceram interlocuções com um conjunto de pesquisas em História da Educação que selecionou as políticas públicas de educação e as diferentes experiências de formação docente como 
temáticas de estudo (NÓVOA, 1991, 1992, 1995, 1999a, 1999b, 2002; NUNES, 2002; DIAS, 2013; VILLELA, 2007; CATANI, 2007; ALVES, 2015; SOUZA, 2010). Nessa linha, de modo mais específico, o foco foi direcionado para o Instituto de Educação (Centro Integrado de Educação Pública - CIEP Brizolão 380 Joracy Camargo), localizado no Município de Belford Roxo, RJ, tendo como recorte temporal os anos 1996 a 2006.

Diante da opção de assumir os debates da historiografia e da História da Educação, cabe enfatizar que a proposta considerou o que Silva e Lemos (2013) alertam em relação aos cuidados com o estudo do passado, sensibilizando o olhar para os acontecimentos ocorridos em outros tempos que não os nossos, questionando aquilo que não nos é (ou não deveria ser) familiar. Para os autores, o esforço teórico-metodológico de abordar "o passado" a partir, e em razão da categoria de "diferentes presentes" torna-se operatório, por um lado, por colocar em relevo algumas daquelas características que passaram a ser consideradas necessidades, possibilidades e exigências sociais de uma delimitação populacional e territorial. Por outro lado, por facultar as condições para que o foco seja projetado também para algumas inquietações relativas ao desejo de transformar o real em algo enigmático, não domesticado, delegando ao pesquisador o zelo de privilegiar diversificadas formas de entrada e discussão ao problema selecionado para análise.

Ancorado nessa perspectiva teórico-metodológica, o trabalho de pesquisa realizado apontou para a importância de considerar que projetar as atenções para o passado significa, fundamentalmente, examinar as ações e as realidades vivenciadas, perante aquilo que era necessário e possível em cotidianos distintos. Portanto, a intenção passou pela organização de um conjunto de preocupações capaz de enfocar as homogeneidades e permanências, mas também as circunstâncias heterogêneas, transitórias e inesperadas que, inclusive, produziam interferências nas maneiras de os sujeitos sociais estabelecerem suas interações.

No que diz respeito à emergência do CIEP Brizolão, estabelecimento voltado para trabalhar a formação docente em Nível Médio, convém assinalar que coincidiu tanto com a emancipação do Município Belford Roxo quanto com a promulgação da Lei de Diretrizes e Bases da Educação Nacional (LDB n. 
9.394/96), que enfatizava a necessidade de que os professores que fossem atuar (ou já atuassem) na Educação Básica tivessem curso superior. Por isso, sobre as fontes, a pesquisa baseou-se na importância do trabalho com a legislação, mas compreendendo que essa análise, isoladamente, não é suficiente, posto que necessita ser entrecruzada com outros indícios investigados em outras bases documentais. Como afirma Faria Filho (1998, p. 123):

[...] é preciso chamar a atenção para o "entorno" à legislação, um emaranhado de práticas e representações que, sem dúvida, uma vez constituídas como objeto de investigações históricas, poderiam muito contribuir para o entendimento do fenômeno educativo em várias dimensões.

Diante desse recorte problematizador, e dentro dos limites deste trabalho, o texto encontra-se dividido em três principais momentos. $\bigcirc$ primeiro concentra as atenções na análise de alguns aspectos referentes às ações de governo que, de algum modo, tencionam regular, padronizar, controlar e fiscalizar os cursos de formação docente no Brasil. $\bigcirc$ segundo explora determinadas circunstâncias que estiveram envolvidas no momento de emersão do CIEP Brizolão, localizado no Município de Belford Roxo, RJ. $\bigcirc$ terceiro momento, redigido à guisa de considerações finais, interessa-se pela discussão de que as políticas públicas educacionais implementadas por esta ou aquela ação de governo não devem ser analisadas somente sob o signo da imposição estratégica e prescritiva. Antes mais, colocar em relevo as experiências educacionais que foram tencionadas em diferentes períodos históricos significa aclarar que houve disputas, negociações e tensões referentes às diferentes formas de preparação para a prática profissional do professor no Brasil, como um todo, e em Belford Roxo, em particular. 


\section{TORNAR-SE PROFESSOR: ENTRE REGULAMENTAÇÕES E (DES) ACORDOS}

Concentrar o foco das atenções na criação de instituições próprias de formação docente - os Institutos de Educação ou Escolas Normais - com capacitação vinculada ao segmento do Ensino Médio e à modalidade de Curso Normal não significa desconsiderar que, historicamente, houve (e permanece havendo) disputas, negociações e tensões relacionadas às diferentes formas de preparação para a prática profissional do exercício docente. A criação de instituições próprias de formação é uma etapa do processo de profissionalização docente e está embasada na ação dos docentes e do Estado. Os primeiros perceberam em tal empreitada a possibilidade da ampliação de seu estatuto, e o segundo almejou sua regulamentação e efetiva supervisão. "Com efeito, a institucionalização de procedimentos de formação, através da criação de Escolas Normais, permitiu, de um lado, o desenvolvimento da profissão docente e a melhoria da posição social de seus membros e, de outro, o estabelecimento de um controle social." (NÓVOA, 1991, p. 124).

Os Institutos de Educação ou Escolas Normais estão no eixo de uma profunda reconstrução da identidade profissional do professor, configurando mudanças que trazem consigo rupturas, mas também continuidades. Aampliação do estatuto dos docentes esteve indissociavelmente ligada ao desenvolvimento das instituições próprias de formação. "O discurso da necessidade de instruir o povo e de formar convenientemente os professores por meio dessas instituições esteve presente ao longo do século XIX, como apontado por diversas pesquisas, sendo reatualizado no século XX." (UEKANE, 2016, p. 17).

Desse quadro geral, é preciso ressaltar que as instituições próprias de formação de professores, embora com a escolarização dos futuros docentes nas mãos, não têm responsabilidade exclusiva em relação aos percursos do exercício do magistério e ao cenário das práticas pedagógicas desenvolvidas nas salas de aula, mas assumiram (e permanecem assumindo) tal imagem nos discursos reformistas, o que configura todo um repertório de análise. A esse respeito, torna-se interessante destacar que, em tempos distintos, a construção do CIEP 380 Joracy Camargo, escola de tempo integral, e a passagem dele a 
Instituto de Educação (CIEP Brizolão 380 Joracy Camargo) foram iniciativas apoiadas por muitos políticos da época que enfatizavam a "missão" da educação e a importância daquele espaço de formação docente tanto para o Município de Belford Roxo quanto para o próprio Estado do Rio de Janeiro.

Desconstruindo tal paradigma, Tardif (2000) sublinha as redes que se fazem nos percursos de formação docente, alertando-nos sobre a desmistificação de uma supremacia absoluta voltada para os espaços formativos escolares e os caminhos lineares de capacitação:

Em seu trabalho, um professor se serve de sua cultura pessoal, que provém de sua história de vida e de sua cultura escolar anterior; ele também se apoia em certos conhecimentos disciplinares adquiridos na universidade, assim como em certos conhecimentos didáticos e pedagógicos oriundos de sua formação profissional; ele se apoia também naquilo que podemos chamar de conhecimentos curriculares veiculados pelos programas, guias e manuais escolares; ele se baseia em seu próprio saber ligado à experiência de trabalho, na experiência de certos professores e em tradições peculiares ao ofício de professor. (TARDIF, 2000, p. 14).

A formação do professor e a constituição de sua identidade profissional estão para além de um sistema formal de ensino e da tutela por meio de uma ou outra instituição, mesmo compreendendo que isso faz parte da realidade discursiva. No caso brasileiro, a LDB n. 9.394/96, por exemplo, em sentido oposto, apresenta regulamentações sobre a chancela do direito a lecionar na educação infantil e nas séries iniciais do ensino fundamental, exaltando intensamente a ampliação da formação institucionalizada. ${ }^{4}$ Assim, seguindo a ideia de redes existentes no processo de capacitação dos professores, afora aquilo que as instituições próprias de formação fornecem de maneira regular e oficial em seus programas e ementas, Alves (1998) também sinaliza:

\footnotetext{
4 Art. 62 da LDB n. 9.394/96 apresenta a seguinte diretriz (alterada pela Lei n. 12.796, de 2013): "A formação de docentes para atuar na educação básica far-se-á em nível superior, em curso de licenciatura, de graduação plena, em universidades e institutos superiores de educação, admitida, como formação mínima para o exercício do magistério na educação infantil e nas quatro primeiras séries do ensino fundamental, a oferecida em nível médio, na modalidade normal."
} 
Não é possível se aceitar a ideia que a formação docente se dá exclusivamente em cursos de formação (ela se dá em múltiplas esferas). Por outro lado, vai se percebendo que ao contrário de serem construídos linear e hierarquizadamente, os conhecimentos - teóricos e práticos-políticos, epistemológicos, pedagógicos, curriculares, didáticos e outros - necessários ao exercício docente são tecidos em redes. (ALVES, 1998, p. 15).

Outro importante aspecto relacionado à não total predominância das instituições próprias de formação docente está na questão de que o professor, antes de assumir propriamente a profissão, já experimenta as especificidades do espaço de atuação futura: a escola. Os professores passam do papel de alunos para o de docentes, levando consigo muitas impressões e concepções delineadas no tempo de escolarização regular.

Como nos aponta Nóvoa (1991, p. 125-126): “No processo de sua entrada na profissão, os docentes efetuam uma role-transition em vez de uma role-reversal e, no início de sua atividade profissional, utilizam referências adquiridas no momento em que eram alunos [...]" Nessa medida, definitivamente, é necessário reconhecer, sem anular a importância das instituições próprias de formação docente e projetando um olhar investigativo sobre elas, que a capacitação dos professores acontece em redes que têm conexão com a vida particular e coletiva. De acordo com Cunha (1989):

$\bigcirc$ professor já nasce inserido em seu cotidiano. A vida diária não está fora da história, mas, ao contrário, está no centro do acontecer histórico. Como todo indivíduo, o professor é simultaneamente um ser em particular e um ser genérico. Isto significa dizer que quase toda a sua atividade tem caráter genérico, embora seus motivos sejam particulares. No seu cotidiano, ele trabalha estas duas forças: as que vêm da generalização de sua função e as que partem dele enquanto individualidade. Nem sempre ambas caminham no mesmo sentido. Muitas vezes é do conflito entre elas que se origina a mudança de atitudes do professor. (CUNHA, 1989, p. 157). 
Conquanto estejamos de acordo com tais ponderações, que enfatizam que a capacitação docente acontece em articuladas e distintas esferas, é urgente retomar o propósito de se colocar o foco na análise das instituições próprias de formação docente. Afinal, no caso da realidade brasileira, por exemplo, a efervescência das discussões sobre a necessidade de mudança no sistema educacional de nosso País, a partir da defesa de uma formação docente para atuação na Educação Básica por meio das Instituições de Ensino Superior (IES), culminou com a Lei de Diretrizes e Bases da Educação Nacional n. 9.394/96 e o Plano Nacional de Educação (PNE) (2001-201 1).

A legislação educacional brasileira, ainda em vigor, a LDB $n$. 9.394/96, trouxe a perspectiva de uma demanda reformista, cuja retórica ficou voltada para a defesa das IES como instituições principais para o exercício de formação docente. O PNE (2001-2011) apresenta alguns indícios de tal movimento e mudança de ênfase:

As IES têm muito a fazer, no conjunto dos esforços nacionais, para colocar o país à altura das exigências e desafios do séc. XXI, encontrando a solução para os problemas atuais, em todos os campos da vida e da atividade humana e abrindo um horizonte para um futuro melhor para a sociedade brasileira, reduzindo as desigualdades. A oferta de educação básica de qualidade para todos está grandemente nas mãos dessas instituições, na medida em que a elas compete primordialmente a formação dos profissionais do magistério; a formação dos quadros profissionais, científicos e culturais de nível superior, a produção de pesquisa e inovação, a busca de solução para os problemas atuais são funções que destacam a universidade no objetivo de projetar a sociedade brasileira num futuro melhor. (BRASIL, 2001).

De início, este, por assim dizer, tom salvacionista ${ }^{5}$ do PNE (20012011 ), explicitado a partir do que está previsto na LDB n. 9.394/96, precisa ser problematizado. A questão do ideal da educação básica de qualidade para todos perpassa por muitos fatores, além da formação dos quadros profissionais

5 Para uma discussão sobre as dimensões salvacionistas que, com frequência incômoda, permanecem conhecendo os seus lugares de enunciação no campo educacional, ver Silva e Bocchetti (2016). 
do magistério mediado pelas IES. Nessa linha, torna-se insuficiente compreender que a educação, sozinha, é capaz de mudar os rumos da sociedade e que os professores possuem "missões" vastas voltadas para a transformação social, inclusive os professores dos cursos de formação docente dos Institutos de Educação ou Escolas Normais, assim como também das IES. Portanto, o delineamento proposto para a formação docente, no caso do Brasil, com metas voltadas para o repasse da responsabilidade para as IES, camufla a raiz da questão.

Os professores, nos discursos reformadores, via de regra, são colocados no centro das preocupações, e a formação docente é percebida como salvação para os problemas da educação (SILVA; BOCCHETTI, 2016). Tal retórica tem um efeito desresponsabilizador, ofertando conforto transitório a partir de algo que está supostamente sendo realizado e mobilizado.

A LDB n. 9.394/96, com suas proposições, e o PNE (2001-201 1), com a definição de metas, voltaram a concentrar o foco na mudança educacional e na reforma como aspectos indispensáveis para uma vangloriada "melhoria" da educação brasileira. $\bigcirc$ ponto central, aqui, é a análise da reforma da escola a partir da formação docente e da pretensa busca de se conseguir resultados apenas adiando a garantia da chancela legal para o direito a lecionar a partir das IES. Talvez, o aumento do número de professores com Ensino Superior não seja garantia absoluta de ensino mais eficaz, apesar de ser usado nos discursos, sublinhado nas estatísticas, vangloriado nos palanques. Como alerta Popkewits (1997, p. 42):

\begin{abstract}
A reforma da escola fica reduzida a soluções como um aumento de temas ou maiores exigências de certificados como evidência da competência do professor. Os relatórios da mudança ou atividade, independente da sua natureza ou profundidade, são considerados como testemunhos de progresso.
\end{abstract}

Com efeito, as reformas educacionais - bradando o tom salvacionista da escolarização do social - vêm sendo enfatizadas como um dispositivo eficaz para obter o "avanço" na política, na economia, na cultura e nos demais campos da vida social (SILVA; BOCCHETTI, 2016). Conforme Lessard (2006) 
nos sinaliza, persiste o ideal de aperfeiçoar a qualidade dos estabelecimentos de ensino para melhor atender às demandas de crescimento cada vez mais contingentes. Compreende-se que a melhoria da eficácia e a ampliação da equidade do ensino passam pela capacidade de fazer com que profissionais preparados ensinem de forma adequada, de acordo com o que aprenderam nos cursos superiores.

Diante dessas expectativas governamentais que dizem respeito às projeções para a alteração de uma nova ordem na formação docente, explicitada pela meta do aperfeiçoamento do sistema educativo como um todo, torna-se cada vez mais urgente pensar se, realmente, resultados mais satisfatórios para a educação básica seriam provenientes da reelaboração dos programas de formação docente, quando ampliados para as IES, minimizando a possível contribuição do Curso Normal ofertado pelos Institutos de Educação ou Escolas Normais.

A esse respeito, voltar as atenções para a LDB n. 9.394/96 constituise como um movimento interessante. Afinal, essa Lei determinou que, até o final de 2006, somente professores com Nível Superior receberiam a chancela legal que os habilitaria para lecionar na Educação Básica, admitindo-se como formação mínima para a atuação na Educação Infantil e nas séries iniciais do Ensino Fundamental a oferecida em Nível Médio, na modalidade Normal. A regulamentação materializada em legislação aparece mesmo sob a ótica de uma realidade plural, constituída por um cenário nacional marcado historicamente pela atuação de professores formados a partir dos Institutos de Educação ou Escolas Normais e, ainda, pelo significativo contingente de professores não habilitados (os chamados "leigos").

Esse movimento de exaltação da necessidade da formação docente voltada para as IES concorreu para que os Institutos de Educação ou Escolas Normais passassem a conviver com o panorama de uma conflituosa crise de identidade, perdendo, gradativamente, a centralidade. Assim, fica evidente que a profissionalização, incluindo a formação docente, não é um processo que acontece de modo endógeno, ou seja, mostra-se incapaz de estar desvinculada do lugar que seus membros ocupam nas relações de saber-poder e do papel que eles jogam na arena política e educacional. 
Perante essas exigências da LDB de 1996 e do Plano Nacional de Educação (2001-2011), este estudo tencionou problematizar algumas das circunstâncias que estiveram (e, em certo sentido, permanecem) presentes na emergência do Instituto de Educação (CIEP Brizolão 380 Joracy Camargo) em questão. Dimensões relacionadas a essa emergência que conheceu os seus acasos do começo no mesmo ano em que a LDB n. 9.394 foi instituída (1996) serão abordadas na próxima seção.

\section{BELFORD ROXO E A EMERGÊNCIA DO INSTITUTO DE EDUCAÇÃO (CIEP BRIZOLÃO 380 JORACY CAMARGO): DIMENSÕES E CIRCUNSTÂNCIAS RELACIONADAS}

Ao colocar o foco na experiência do Instituto de Educação de Belford Roxo (CIEP Brizolão 380 Joracy Camargo), é preciso considerar que a singularidade não exclui a percepção global que envolve o objeto. Nessa linha, a variação das escalas de observação do fenômeno estudado afigurase como uma estratégia analítica interessante. Afinal, "variar a objetiva não significa apenas aumentar (ou diminuir) o tamanho do objeto no visor, significa modificar sua forma e sua trama." (REVEL, 1998, p. 20). 
Mapa 1 - Regiões de governo e municípios do Estado do Rio de Janeiro

1- Rio de Janeiro

3- Mesquita

4- Nilópolis

5 - São Joåo de Meriti

6 - Itaguaí

7 - Seropédica

9 - Japerí

10 - Queimados

12 - Duque de Caxias

13 - Magé

14 - Guapimirim

15 - Cachoeiras de Macacu

16 - Rio Bonito

17 - Tanguá

18 - Maricá

19 - Itaboraí

20 - São Gonçalo

21 - Niterói

acacu

.
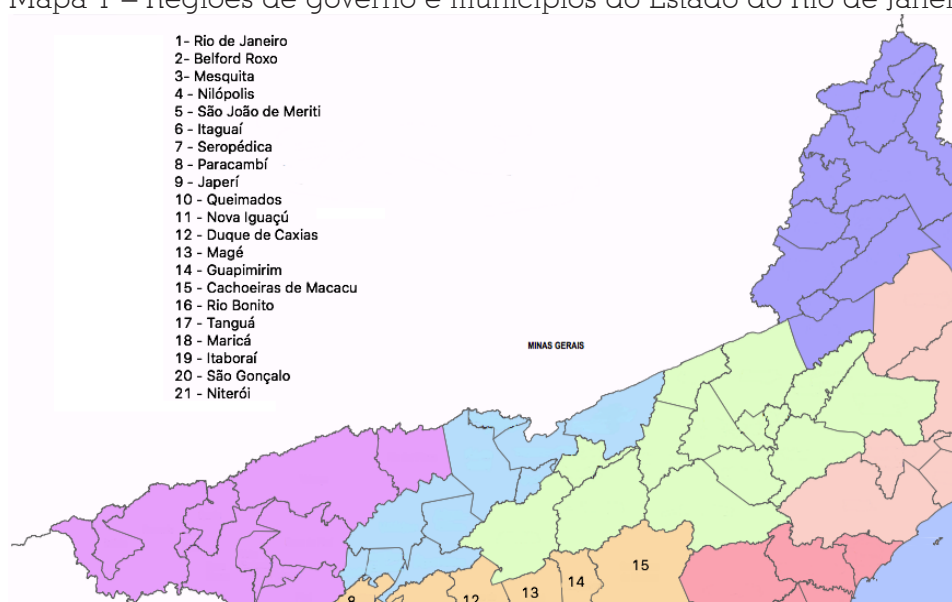
setores financeiro, comercial, educacional e de saúde, bem como órgãos e instituições públicas. ${ }^{7}$

No que se refere especificamente a Belford Roxo, além de pertencer à região Metropolitana, é considerado um dos municípios da chamada Baixada Fluminense ${ }^{8}$ (Mapa 2), uma região do Estado conceituada, em sentido amplo, sob o ponto de vista geográfico, como o espaço de planícies entre a Serra do Mar e o litoral, desde Itaguaí até Campos dos Goytacazes. Porém, em sentido mais usual e cotidiano, é o conjunto dos municípios que se localizam ao norte do Município do Rio de Janeiro, na região antigamente conhecida como Baixada da Guanabara.

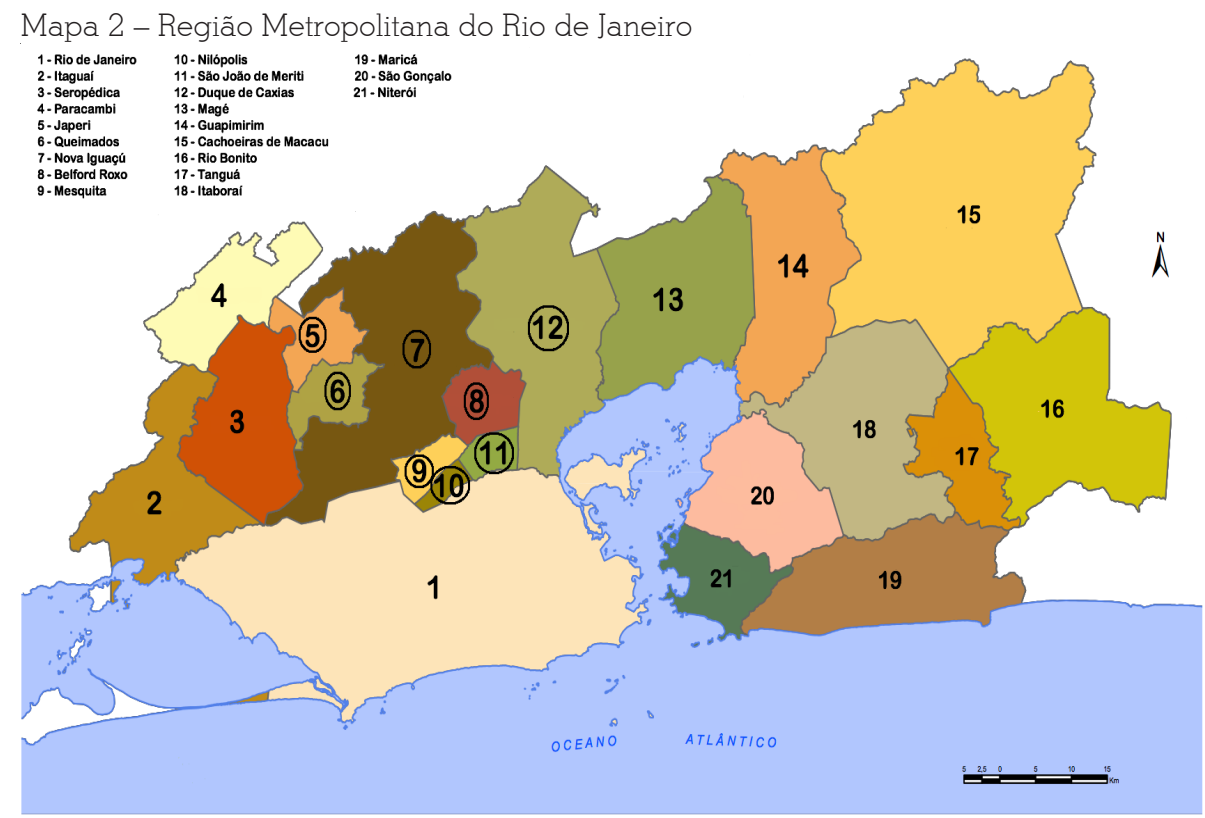

Fonte: Fundação Ceperj (2017)

uso dos índices estatísticos neste estudo esteve ancorado nos alertas firmados por De Certeau (1994), que destaca que as estatísticas apreendem o material das práticas e não a sua forma, sinalizando que, muito mais do que "dados", os números são construções atravessadas pelas intencionalidades de quem elaborou, aplicou e, finalmente, colocou em circulação os mapeamentos.

8 A Baixada Fluminense refere-se a uma divisão não oficial e administrativa, com imagem de uma região de grandes problemas sociais e de violência urbana. Das regiões em que costuma ser dividido o Estado do Rio de Janeiro, é a segunda mais populosa, com mais de três milhões de habitantes, somente sendo superada pela capital (BAIXADA FLUMINENSE, 2017). 
Em relação ao processo de formação administrativa, o distrito com a denominação de Belford Roxo foi criado pelo Decreto Estadual n. 641, de 15 de dezembro de 1938, sendo subordinado ao Município de Nova Iguaçu. Pelo Decreto-Lei Estadual n. 1.055, de 31 de dezembro de 1943, confirmado pelo n. 1.056, da mesma data, o Distrito de Belford Roxo perdeu parte do território, sendo desmembrado para constituir o novo Município de Duque de Caxias e anexado ao Distrito de Imbariê, do mesmo Município. Somente foi elevado à categoria de município, com denominação de Belford Roxo e de forma emancipada, por meio da Lei Estadual n. 1.640, de 03 de abril de 1990, quando foi definitivamente desmembrado de Nova Iguaçu.

processo de emancipação e sustentação do Município de Belford Roxo, no presente estudo, foi relacionado à hipótese de que esteve integrado, de alguma forma, com a luta política pela fundação do Instituto de Educação. Isso porque o espaço de escola de formação básica regular já existente, em arquitetura de CIEP, foi passado à categoria de instituição de formação de professores em 1996, também mediante disputas e constrangimentos, em tempo especial de reorganização administrativa de Belford Roxo.

A partir da investigação realizada, ${ }^{9}$ foi possível levantar a população estimada em 2016: 494.141 moradores, com área territorial de 77.815 km². Seu Produto Interno Bruto (PIB) per capita a preços correntes, em 2013, situouse em $R \$ 13.247,85$ com valor do rendimento nominal mediano mensal (per capita dos domicílios particulares permanentes) de $\mathrm{R} \$ 402,50$. No mapa de pobreza e desigualdade dos municípios brasileiros, apresentado em 2003 pelo IBGE, mostrou-se em situação preocupante, ocupando o quinto lugar, atrás de Japeri, Queimados, Tanguá e Magé.

Apresentando características peculiares de carência no que se refere aos aspectos do desenvolvimento humano e qualidade de vida, a localidade possui escolas em praticamente todas as regiões, apesar de a educação estar longe de resultados satisfatórios e do acolhimento pleno das demandas (para o ensino fundamental - 45 escolas estaduais e 48 escolas municipais; para o 9 Os índices estatísticos apresentados e ressaltados no estudo em questão foram pesquisados no
site: <http://cidades.ibge.gov.br/xtras/perfil.php?codmun=330045>. Acesso em: 14 nov. 2017 . 
ensino médio - 33 escolas estaduais; ${ }^{10}$ para a educação infantil - três escolas estaduais e 22 escolas municipais). $\bigcirc$ Município conta, ainda, com polos da Fundação Cecierj ${ }^{11}$ (dois polos de pré-vestibular e um polo do consórcio Cederj) e duas instituições particulares de ensino superior (a Faculdade de Belford Roxo, Fabel, e a Associação Brasileira de Ensino Universitário, UNIABEU).

Seguindo com o desafio de colocar as lentes sobre Belford Roxo, tornase oportuno neste momento situar o Instituto de Educação (CIEP Brizolão 380 Joracy Camargo). A esse respeito, vale salientar que, desde a sua fundação, em 1996, esse Instituto de Educação faz uso de uma arquitetura que foi redirecionada para ele, mas não edificada exclusivamente em decorrência de seu projeto e sua razão de existir. No caso, ele é até no nome um "Brizolão", 12 um Centro Integrado de Educação Pública (CIEP) e traz consigo as características de uma política educacional específica que esteve voltada para a escola de tempo integral.

Nessa linha de análise, é necessário exaltar que os CIEPs, ${ }^{13}$ erguidos durante o governo de Leonel de Moura Brizola (1983 a 1987 e 1991 a 1994), no Estado do Rio de Janeiro, pelo Partido Democrático Trabalhista (PDT), foram idealizados por Oscar Niemeyer na concepção arquitetônica e planejados por Darcy Ribeiro na parte organizacional e pedagógica, mediante a forma de $1^{\circ}$ e $2^{\circ}$ Programa Especial de Educação ( $1^{\circ} \mathrm{PEE}$ e $\left.2^{\circ} \mathrm{PEE}\right)$. Especificamente sobre os CIEPs, Mignot (2001, p. 153) registra o seguinte:

\footnotetext{
10 O Instituto de Educação (CIEP Brizolão 380 Joracy Camargo) está contabilizado no grupo de escolas estaduais de ensino médio. Muitos não sabem que é uma instituição de formação docente, pois seu cadastro no senso escolar está configurado pelo nome CIEP Brizolão 380 Joracy Camargo e não Instituto de Educação (nome do tempo da fundação e conhecido pelos sujeitos sociais).

11 consórcio Cederj é uma parceria da Fundação Cecierj (Centro de Ciências e Educação Superior do Estado do Rio) com municípios e seis universidades públicas (UERJ, UNIRIO, UFF, Rural, UFRJ e UENF), que oferecem sete cursos de licenciatura e dois normais, na modalidade a distância. Os polos servem de apoio ao aprendizado, onde os alunos podem tirar dúvidas com tutores e assistir a aulas práticas. A infraestrutura dos polos é oferecida pelas prefeituras das cidades onde estão localizados. A unidade de Belford Roxo, em 2009, recebeu três salas de tutoria, três laboratórios, uma sala de aula e uma sala de estudos (BLOG ROXO POR BERFORD ROXO, 2017). 12 Os Centros Integrados de Educação Pública (CIEPs) foram o principal projeto educacional dos dois governos de Leonel de Moura Brizola no Estado do Rio de Janeiro (1983 a 1987 e 1991 a 1994) e ficaram conhecidos, popularmente, como Brizolões, seguindo o desejo de Darcy Ribeiro.

13 Dentro dos limites e recortes deste estudo, optamos por sistematizar apenas algumas das muitas discussões relacionadas ao projeto dos CIEPs e suas implicações para o campo da História da Educação. Para um adensamento daquilo que foi explorado neste artigo, consultar Faria (1991, 201 1), Mignot (2001, 2004), Chagas (2016) e Cavalieri e Coelho (2003).
} 
Sintetizam uma dada concepção de educação que despertou fascínio, perplexidade e rejeição. Os CIEPs pretendiam engendrar uma mudança radical entre a "escola do futuro" e a rede múltipla, diferenciada e rica de problemas. A identidade da escola de tempo integral foi se desenhando numa dupla perspectiva - como modelo às escolas públicas do futuro e no confronto com as instituições de ensino que compunham a rede pública [...]

Com efeito, o $1^{\circ} \mathrm{PEE}$ e o $2^{\circ} \mathrm{PEE}$, a partir de suas diretrizes enfaticamente exaltadas, buscaram atingir a meta de implementação de 500 novas escolas, pelo menos uma em cada município. "Em maio de 1985 inaugurou-se, na capital do estado do Rio de Janeiro, o primeiro CIEP. Durante os anos 80 e 90, em dois períodos governamentais (1983-1987 e 1991-1994), foram construídos e postos em funcionamento 506 CIEPs." (CAVALIERI; COELHO, 2003, p. 148).

É importante considerar que o CIEP 380 Joracy Camargo ${ }^{14}$ foi edificado em 1993, mas que, depois de 1996, mesmo ainda pertencendo à Secretaria de Educação do Estado e mantendo parte de seu quadro de professores, foi redefinindo-se e dedicando-se ao movimento da formação docente em nível médio. Sobre o ano de construção do CIEP, em 1993, cabe uma incursão interessante, pois, de acordo com Mignot (2001, p. 161), "[...] evidencia que o governo estava atento ao calendário eleitoral, pois as obras obedeceram ao ritmo das eleições municipais e estadual."

A partir de então, ao final do segundo governo de Brizola, ocorreu a municipalização de determinados CIEPs (alguns ainda permanecendo com o horário integral, mesmo a partir de inferências na prática pedagógica e na proposta inicial), o abandono de outros (restando apenas a arquitetura) e, ainda, a experiência de redirecionamento da estrutura física, sob a guarda do Estado, para outros fins. Com isso, os CIEPs que ficaram, de uma forma ou de outra, acabaram recebendo também o estigma de escolas para alunos sem cuidados familiares e marginalizados, geralmente se caracterizando como instituições situadas em regiões abandonadas pelo poder público. Cabe

14 O atual CIEP Brizolão 380 Joracy Camargo, conhecido no Município como Instituto de EducaÇão, já foi CIEP 380 Joracy Camargo e, temporariamente, CIEP - Instituto de Educação de Belford Roxo. 
assinalar, portanto, que aqui está mais uma característica presente na História do Instituto de Educação de Belford Roxo (CIEP Brizolão 380 Joracy Camargo), pois com o processo pelo qual passaram (e ainda passam) os CIEPs, ficou nele também a marca de que tem algo daquilo que "não deu certo" ou que está situado em área de risco.

A lógica que subjaz, então, é a de que o Instituto de Educação (CIEP Brizolão 380 Joracy Camargo) se mostra como uma instituição mal localizada, que fica na Rua Almeida Santos, número 0, Centro de Belford Roxo. A citada rua possui 93,50\% de endereços residenciais e está localizada no bairro de Santo Antônio da Prata. Embora no Centro, a rua não é de fácil acesso ou principal. A instituição em estudo, de forma especial, não possui mesmo uma significativa acessibilidade, ficando no alto de uma ladeira, que é caracterizada, principalmente, pelo fluxo dos moradores e dos normalistas uniformizados.

As considerações feitas suscitam a exploração de informações sobre a arquitetura pensada para os CIEPs. Cada um deles, incluindo o próprio CIEP 380 Joracy Camargo, possui três blocos. ${ }^{15}$ No bloco principal, estão as salas de aula (18 a 20 salas), o centro médico, a cozinha, o refeitório e um grande pátio coberto. No segundo bloco, estruturam-se o ginásio e a quadra polivalente. E, ainda, no terceiro bloco, fica a biblioteca e sobre ela as moradias para alunos residentes. Tudo detalhadamente previsto, especificando-se no projeto de cada unidade os itens materiais de composição do ambiente. É interessante observar que no CIEP 380 Joracy Camargo, assim como ocorreu com muitas outras unidades, tudo foi reconfigurado e, após a reutilização do espaço para outra finalidade, a otimização das dependências foi sendo feita a partir dos novos usos atribuídos a cada espaço.

No caso do Instituto de Educação de Belford Roxo (CIEP Brizolão 380 Joracy Camargo), inicialmente em 1996, havia no mesmo espaço a dinamização do Curso Normal em Nível Médio e, ainda, o Ensino Fundamental, em dois horários (não mais em sistema integral), a partir do qual os normalistas faziam seus

\footnotetext{
15 Para os terrenos onde não fosse possível instalar todas as três construções que integravam o Projeto-padrão, foi elaborada uma alternativa, denominada CIEP compacto, composta apenas pelo prédio principal, ficando no terraço a quadra coberta, os vestiários, a biblioteca e as caixasd'água.
} 
estágios. Isso trazia certa otimização para as dependências e a motivação para a tentativa de ações em prol da preservação delas. Entretanto, após tal período, a instituição passou a se dedicar exclusivamente à formação de professores como Instituto de Educação, e a ociosidade do espaço agravou-se. Além disso, gradativamente, a procura de candidatos para a oferta do Curso Normal foi se reconfigurando, mediante as exigências da legislação sobre a carga horária do curso ofertado, demonstrando um tempo de apogeu e outro de baixa procura, reduzindo e tornando a "casa grande demais para poucos moradores".

\section{CONSIDERAÇÕES FINAIS}

Por meio deste estudo concretizado, foi possível perscrutar indícios de que os dispositivos que configuraram a promulgação da LDB n. 9.394/96 investiram (e, de certo modo, permanecem investindo) numa concepção de formação docente fundamentada pela defesa da necessidade de um diploma chancelado por uma Instituição de Ensino Superior que comprove e autorize a habilitação para o exercício do magistério. Desse modo, o dispositivo legal, de uma forma ou de outra, tem-se apresentado alinhado aos (des)caminhos da profissionalização docente.

Assim, a ênfase adotada parece avançar para a legitimação da docência, mediante a crescente fidelização de um conjunto de conhecimentos especializados e a inerente divulgação da realização de um trabalho da mais alta importância social (o que traz implícita a necessidade de ampliar o tempo de formação). Entretanto, enquanto isso, as ações de governo perpetuam por meio de tal processo formas de ampliar o controle sobre a categoria docente, tutelando a formação dos profissionais para o magistério e os rumos da instituição escolar.

A partir da reflexão que emerge, é interessante destacar que alguns aspectos relativos à chancela para o direito a lecionar foram sempre defendidos por uns e intensamente perseguidos por outros, ainda que com finalidades diversas. Portanto, é possível afirmar que esse processo de discussão sobre 
as políticas de formação docente não se fez (ou se faz) de forma linear ou consensual e persiste em "diferentes presentes" (SILVA; LEMOS, 2013).

No seu conjunto, a aprovação da LDB n. 9.394/96 assinalou um momento de transição significativa para a educação brasileira e para a história da profissão docente. Enfim, a transição normativa da legislação educacional nacional fixou, em relação aos profissionais da educação, as finalidades e fundamentos de sua formação; os níveis e o lócus da formação docente e de "especialistas"; os cursos mantidos; a carga horária; a valorização do magistério e o sentido da experiência docente. Entretanto, é necessário reforçar que a legislação, além de "ordenamento jurídico", deve ser percebida também como "prática social" e "linguagem" (FARIA FILHO, 1998).

Desse quadro geral, as percepções projetadas para a experiência do Instituto de Educação de Belford Roxo (CIEP Brizolão 380 Joracy Camargo), fundado em 1996, nas dependências de um CIEP, exatamente quando o Município foi emancipado e a LDB n. 9.394/96 aprovada, apresentam indícios de que, na política educacional brasileira, os pretensos avanços legais voltados para a ampliação da formação acadêmica dos professores da Educação Infantil e Séries Iniciais parecem se opor a significativos embates pragmáticos que esbarram em realidades das mais distintas e processos dos mais diversificados. Nessa medida, em Belford Roxo, no ano de sua emancipação, enquanto a legislação exaltava a prerrogativa da formação em Nível Superior, o Município, mediante uma realidade social e política, contemplava a novidade da criação de uma instituição própria de formação docente em Nível Médio.

Como neste estudo se pôde analisar, há muitas particularidades no que se refere aos estatutos e planos de carreira do magistério. A legislação, tendo como exemplo o município estudado e a instituição colocada em foco, não é cumprida no que diz respeito aos seguintes aspectos: ingresso exclusivamente por concurso público de provas e títulos (persiste a contratação de profissionais temporários em período de eleições); aperfeiçoamento profissional continuado, inclusive com licenciamento periódico remunerado para esse fim; piso salarial profissional (que não é ainda justo e existe apenas para alguns); progressão funcional baseada na titulação ou habilitação e na avaliação do desempenho; período reservado aos estudos, planejamento e avaliação incluído na carga 
horária. Tais dimensões indiciam algumas das disputas, negociações e tensões que, de maneira cada vez mais intensa, interferiram (e permanecem interferindo) nos modos de ser/fazer/se tornar docente daquela região. Igualmente, sinalizam para a necessidade de que outros investimentos de pesquisa sejam empreendidos com o objetivo de investigar as maneiras como os dispositivos constantes a uma legislação nacional, no caso a LDB n. 9.394/96, são apropriados e resignificados de acordo com as características de outras tantas localidades que, juntas, compõem este nosso surpreendente e, no mais das vezes, (des)conhecido País.

\section{REFERÊNCIAS}

ALVES, N. Trajetórias e redes na formação de professores. Rio de Janeiro: DP\&A, 1998.

ALVES, R. M. de S. (Des)caminhos da profissão docente: sobre a experiência do curso PARFOR no IFMA/Campus Codó (2010-2014). 2015. Dissertação (Mestrado em Educação)-Universidade Federal do Rio de Janeiro, Rio de Janeiro, 2015.

BAIXADA FLUMINENSE. Rio de Janeiro: $\bigcirc$ Portal da Cidade Maravilhosa. Disponível em: <http://www.oriodejaneiro.com/baixadafluminense.htm>. Acesso em: 14 nov. 2017.

BLOG ROXO POR BERFORD ROXO. Belford Roxo abre polo de graduação a distância. Disponível em: <https://blogroxo.wordpress.com/2009/07/24/ belford-roxo-abre-polo-de-graduacao-a-distancia/>. Acesso em: 14 nov. 2017.

BRASIL. Lei n. 9.394, de 20 de dezembro de 1996. Estabelece as diretrizes e Bases da Educação Nacional. Diário Oficial da União, Brasília, DF, 20 dez. 1996.

BRASIL. Lei n. 10.172, de 09 de janeiro de 2001. Aprova o Plano Nacional de Educação e dá outras providências. Diário Oficial da União, Brasília, DF, 09 jan. 2001.

CATANI, D. B. Estudos de História da Profissão Docente. In: LOPES, E.; FARIA FILHO, L. M de; VEIGA, C. (Org.). 500 anos de educação no Brasil. Belo Horizonte: Autêntica, 2007. 
CAVAliERE, A. M.; COELHO, L. M. Para onde caminham os Cieps? Uma análise após 15 anos. Cadernos de Pesquisa, n. 119, p. 147-174, jul. 2003.

CHAGAS, M. Animação cultural: a inovação dos CIEPs-RJ nos anos 1980. Curitiba: Editora e Livraria Appris Ltda., 2016.

CUNHA, M. I. O bom professor e sua prática. Campinas: Papirus, 1989.

DE CERTEAU, M. A invenção do cotidiano. Rio de Janeiro: Vozes, 1994.

DIAS, A. Apostolado Cívico: a Função Social do Magistério de Ensino Secundário (1931-1942). Revista Contemporânea de Educação, v. 8, n. 15, jan./ jul. 2013.

FARIA FILHO, L. M. de. A legislação escolar como fontes para a história da educação: uma tentativa de interpretação. In: FARIA FILHO, L. M. de. (Org.). Educação, modernidade e civilização. Belo Horizonte: Autêntica, 1998.

FARIA, L. Chaguismo e Brizolismo: territorialidades políticas da escola fluminense. Rio de Janeiro: Quartet, 2011.

FARIA, L. CIEP, A utopia possível. São Paulo: Livros do Tatu, 1991.

FUNDAÇÃO CEPERJ. Estado do Rio de Janeiro divisão político-administrativa. <http://www.ceperj.rj.gov.br/ceep/info_territorios/divis_politico_administrativo.html>. Acesso em: 14 nov. 2017.

LESSARD, C. A universidade e a formação profissional dos docentes: novos questionamentos. Educação e Sociedade, Campinas, v. 27, n. 94, p. 201227, jan./abr. 2006.

MIGNOT, A. C. V. Escolas na vitrine: Centros Integrados de Educação Pública (1983-1987). Estudos Avançados, São Paulo, v. 15, n. 42, p. 153-168, 2001.

MIGNOT, A. C. V. Monumento à Educação: escola pública de tempo integral. Revista Rio de Janeiro, Rio de Janeiro, maio/dez. 2004.

NÓVOA, A. Formação de Professores e Trabalho Pedagógico. Lisboa: Educa, 2002.

NÓVOA, A. (Org.). Vidas de professores. Porto: Porto Editora, 1992.

NÓVOA, A. Os professores e sua formação. 2 ed. Lisboa: Publicações Dom Quixote, 1995. 
NÓVOA, A. Para o estudo sócio histórico da gênese e desenvolvimento da profissão docente. Teoria e Educação, n. 4, 1991.

NÓVOA, A. Os professores na virada do milênio: do excesso dos discursos à pobreza das práticas. Educação e Pesquisa, São Paulo, v. 25, n. 1, jan./jun. 1999a.

NÓVOA, A. Profissão Professor. Porto Alegre: Porto Editora, 1999b.

NUNES, C. Ensino normal - formação de professores. Rio de Janeiro: DP\&A, 2002.

POPKEWITZ, T. S. Reforma Educacional: uma política sociológica - poder e conhecimento em educação. Trad. Beatriz Affonso Neves. Porto Alegre: Artes Médicas, 1997.

REVEL, J. (Org.). Jogos de Escala: a experiência da microanálise. Rio de Janeiro: FGV, 1998.

SILVA, J. C. S.; BOCCHETTI, A. A Revolução dos bichos e o convite para estranhar algumas certezas na modernidade educacional. In: LEMOS, D. C. de A. (Org.). Distopias e Educação: entre ficção e ciência. Juiz de Fora: Editora da UFJF, 2016.

SILVA, J. C. S.; LEMOS, D. C. de A. A História da Educação e os desafios de investigar outros presentes: algumas aproximações. In: FERRERIA, M. S.; XAVIER, L. N.; CARVALHO, F. G. de (Org.). História do Currículo e História da Educação: interfaces e diálogos. Rio de Janeiro: Mauad/FAPERJ, 2013.

SOUZA, F. L. M. Qualificar, Capacitar, Habilitar: a educação e a produção de sujeitos outros, no Ceará do século XX (1987-2007). 2010. Tese (Doutorado em Educação) - Programa de Pós-Graduação em Educação Rio de Janeiro/ UERJ, 2010.

TARDIF, M. Saberes profissionais dos professores e conhecimentos universitários. Revista Brasileira de Educação, n. 13, jan./abr. 2000.

UEKANE, M. N. Com o bom professor tudo está feito, sem ele nada se faz: a Escola Normal e a conformação do magistério primário no Distrito Federal (1892-1912). Tese (Doutorado em Educação)-Universidade Federal Fluminense, Niterói, 2016. 
VILLELA, H. de O. S. O Mestre-Escola e a Professora. In: LOPES, E.; FARIA FILHO, L. M. de; VEIGA, C. (Org.). 500 anos de educação no Brasil. Belo Horizonte: Autêntica, 2007.

Recebido em:: 14 de novembro de 2017

Aceito em:: 02 de abril de 2018

Endereço para correspondência: Avenida Pasteur, 250, Praia Vermelha, 22290-240, Rio de Janeiro, Rio de Janeiro, Brasil; claudiosooma@gmail.com 
